\title{
Stage IIIC Appendix Carcinoma AJCC v8
}

National Cancer Institute

\section{Source}

National Cancer Institute. Stage IIIC Appendix Carcinoma A/CC v8. NCI Thesaurus. Code C134128.

Stage IIIC includes: Any T, N2, M0. N2: Four or more regional lymph nodes are positive. M0: No distant metastasis. (AJCC 8th ed.) 